ELECTRON MICROSCOPY

High Volitage at NPL

from a Correspondent

THE six AEI $1 \mathrm{MeV}$ electron microscopes (installed at UKAEA, Harwell, the National Physical Laboratory, Imperial College, the Universities of Oxford and Birmingham and the British Iron and Steel Research Association, Sheffield) plus the $1 \mathrm{MeV}$ JEOL machine at the Central Electricity Generating Board, Berkeley, and the original $750 \mathrm{keV}$ instrument in Cambridge represent a UK investment in high voltage electron microscopy far exceeding that of any other country. About eighty peoplemostly materials scientists using these various instruments and a few biologists - attended a conference organized by the Institute of Physics and the Royal Microscopical Society in conjunction with the National Physical Laboratory at Teddington from September 22 to 23 .

Dr A. Howie (University of Cambridge) reviewed recent progress in understanding the penetration of electron beams in crystals and the remarkable channelling effects occurring above the "critical voltage". This voltage and related interference fringe spacings can be accurately measured to give information about lattice potentials as was shown for gold by Dr J. Steeds (University of Bristol) and for uranium by Drs B. Hudson and A. J. E. Foreman (UKAEA, Harwell). Local temperatures or alloy composition and order can also be determined in this way. Dr E. Butler (Imperial College, London) showed that in nickel-gold alloys 1 per cent compositional change could be detected over distances of about $1 \mu$. Use of a mini lens to reduce the size of the illuminating spot to perhaps $0.1 \mu$ could make this a very powerful microanalysis technique. The discussion indicated that an improved theory which takes account of non-systematic reflexions would be useful for this work.

Above the threshold energy at which the fast electrons can knock atoms out of their lattice sites, the high voltage microscope is unrivalled for radiation damage studies in situ. Void growth, which causes serious swelling problems in fast reactor materials, can be simulated in the microscope at a rate $10^{4}$ faster than in the reactor (Dr K. R. Williams et al., CEGB). Accurate knowledge of flux density in the beam and temperature rise in the specimen are essential for quantitative interpretation of these experiments, as was pointed out by Dr M. J. Makin (UKAEA, Harwell).

The transparency of crystals several microns thick to fast electrons allows in situ experiments which are reasonably typical of bulk materials. Results presented included recrystallization processes in copper alloys (Dr R. Ray et al., University of Birmingham), growth of strain-induced martensite in a titaniumzirconium alloy (Drs H. Flower and P. Swann, Imperial College, London) and an interesting film of dislocation motion during creep of polycrystalline aluminium (Drs K. F. Hale and M. Henderson Brown, NPL). The possible role of point defects in these experiments when the damage threshold energy is exceeded has not yet been assessed.

High voltage microscopes usually have more available space near the specimen which, in addition to the greater penetration of the electron beam, makes them very suitable for in situ experiments involving special stages. Some of these experiments were surveyed by Professor U. Valdré (University of Bologna) and several new straining stages and environmental cells were described. The latter have been used in studies of cement hydration (Dr D. Allinson, NPL), the reduction of haematite (Drs N. Tighe and P. Swann, Imperial College, London) and the observation of $70 \AA$ fringes in wet, partially stained catalase (Drs P. R Ward and R. F. Mitchell, University of Cambridge).

Dr A. Glauert (University of Cambridge) listed the chief advantages of the high voltage microscope in biology as the ability to observe wet (but not living) specimens and to obtain both better resolution and, with stereo methods, a better three-dimensional picture of the structure in thick specimens. The ionization damage in organic materials is re- duced at higher voltages but, as the polymer work of Drs M. J. Richardson and K. Thomas (NPL) demonstrated, this is often cancelled by the increased exposure time required with the photographic plates currently used.

Professor J. M. Cowley (Arizona State University) described a $1 \mathrm{MeV}$ transmission scanning microscope now under construction and emphasized the advantages (chiefly reduced chromatic aberration and improved signal processing) which this technique has over conventional microscopy. This scanning instrument, which operates below the damage threshold, may well (at the cost of some resolution) offer significant advantages for the transmission studies of thick crystals. Its role at higher voltages, whether or not the probable damage produced is of interest, is rather more uncertain and Professor Cowley's results will be awaited with interest. In the meantime, the bold initiative which placed the high voltage conventional microscopes at the disposal of workers in Britain is being followed up with imagination and vigour.

\section{HEPATITIS}

\section{Among Drug Addicts}

from our Medical Virology Correspondent TRANSMISSION of viral hepatitis through the communal use of syringes and needles by addicts for the injection of

\title{
Messenger RNA and the Endoplasmic Reticulum
}

THE elucidation of the way in which messenger RNAs, transcribed in the nucleus of eukaryotic cells, are matured, packaged and transported to the cytoplasmic translation machinery is one of the great challenges of cell biology. Over the past several years evidence has been accumulated which suggests that messenger RNAs occur in cell nuclei in the form of ribonucleoprotein particles -so-called informosomes-and in Nature New Biology next week Faiferman, Cornudella and Pogo report experiments with Krebs ascites cells which, they believe, indicate that these ribonucleoprotein particles migrate to the cytoplasm and become associated with the endoplasmic reticulum.

Faiferman and his colleagues gently lysed Krebs cells which had been labelled with RNA precursors and, by differential centrifugation, isolated the cell nuclei to which remained attached most of the cell's endoplasmic reticulum. After disrupting the nuclei in a French press, the nuclear chromatin was pelleted and the supernatant was found to contain 40-50S ribonucleoprotein particles as well as fragmented reticulum. The 40-50S particles are made in the presence of low doses of actinomycin D which block ribosomal RNA synthesis but cordycepin, which blocks messenger RNA synthesis in HeLa cells, blocks the synthesis of these particles in Krebs cells. To eliminate the possibility that the $40-50 \mathrm{~S}$ particles are of mitochondrial origin, Faiferman and his colleagues have shown that their synthesis is not affected by ethidium bromide, which specifically inhibits the transcription of mitochondrial DNA.

Pulse chase experiments reveal that in the presence of amino-acids the 40-50S particles are rapidly chased into the endoplasmic reticulum. By contrast, when the cells are starved of aminoacids not only are the $40-50 \mathrm{~S}$ particles broken down in the cytoplasm but also large numbers of ribosomes, which are normally attached to the reticulum, are found free in the cytoplasm. Faiferman et al. suggest therefore that the attachment of ribosomes and the 40-50S particles containing messenger are concurrent events. In short, they believe that messenger RNA is delivered to the reticulum in a $40-50 \mathrm{~S}$ particulate riboprotein complex. 